\title{
Interfaces e deslocamentos: feminismos, direitos, sexualidades e antropologia*
}

\author{
Lia Zanotta Machado**
}

\section{Resumo}

Este artigo tem como objetivo identificar e analisar as diferentes questões e interfaces entre os estudos antropológicos sobre gênero e sexualidade e os movimentos sociais pelos direitos das mulheres e pelos direitos à diversidade sexual no Brasil. Entendo que esses estudos, especialmente nas últimas duas décadas, têm ampliado suas questões, no sentido da corporalidade, do self, da subjetividade, da agência, dos sentimentos e afetos. Sempre reforçando relações de gênero como diferentes posiçõesde poder $e$ hierarquia, o conceito de gênero é entendido como tornando-se ou podendo tornar-se em outra forma, não mais identidades, mas identificações, propondo uma ruptura das dicotomias como a heterossexualidade $e$ a homossexualidade, masculinidade $e$ feminilidade. Esses estudos revelam os desafios políticos entre, de um lado, a luta pelos direitos humanos das mulheres e pela diversidade sexual $e$, de outro lado, a luta pela diversidade cultural, bem como os efeitos políticos da escolha de diferentes metodologias antropológicas.

Palavras-chave: Antropologia, Feminismo, Diversidade Sexual, Gênero, Direitos Humanos, Diversidade Cultural.

\footnotetext{
* Recebido para publicação em 10 de março de 2014, aceito em 25 de maio de 2014.

** Professora Titular de Antropologia da Universidade de Brasília. liazm@yahoo.com.br
} 
Interfaces and Displacements: Feminisms, Rights, Sexualities and Anthropology

\begin{abstract}
This article aims to identify and analyze different issues and interfaces between anthropological studies on gender and sexuality, and social movements for women's rights and for rights for sexual diversity in Brazil. I argue that these studies, especially on the last two decades, have enlarged their issues, towards corporeality, self and subjectivity, agency, feelings and affects. Always reinforcing gender relations as different positions in power and hierarchy, the concept of gender is understood in the mode of becoming or becoming otherwise, no more identities, but identifications, proposing a rupture of dichotomies as heterosexuality and homosexuality, masculinity and femininity. These studies reveal the political challenges between the fight for human rights of women and sexual diversity and the fight for cultural diversity, as well as political effects from different choices of anthropological methodologies.
\end{abstract}

Key Words: Anthropology, Feminism, Sexual Diversity, Sexuality, Gender, Human Rights, Cultural Diversity. 
Meu objetivo é refletir e analisar as interfaces entre estudos antropológicos de gênero e sexualidade no Brasil, $e$ as implicações da circulação no campo acadêmico das reivindicações por direitos pelos movimentos feministas e pelos movimentos pela diversidade sexual.

A forma, que ora escolho, é a de apresentar como se configuram as contribuições dos movimentos sociais para os estudos antropológicos de gênero e sexualidade. E, especialmente, como se delineiam e se configuram os embates e os desafios postos pelos movimentos nas interlocuções com os saberes antropológicos. Como não me debruçarei sobre as produções dos pesquisadores e pesquisadoras que tanto contribuíram, meu foco será em perspectiva ampla, correndo o risco de um sobrevoo, mas buscando abordar as questões que configuram temas relevantes entre pesquisadores $e$ pesquisadoras de gênero e sexualidade $e$ formas de articular a perspectiva antropológica $e$ os questionamentos políticos pela obtenção de direitos.

Começo por apontar como os estudos antropológicos de gênero e sexualidade absorveram em suas discussões teóricas $e$ acadêmicas questões vivamente postas pelos movimentos feministas e pelos movimentos LGBT ou LGBTT (lésbicas, gays, bissexuais, travestis, transexuais e transgêneros). Resumo o que entendo como as contribuições mais fortemente reconhecidas, sem deixar de apontar que as apresento do meu ponto de vista e que darei maior visibilidade aos estudos feministas de gênero, dada minha inserção nesse espaço. Contudo, sublinho nessas duas últimas décadas, a relevância da circulação de temas e conceitos teóricos entre os campos de estudos de gênero e de sexualidade.

Além das contribuições e diálogos entre saberes antropológicos, estudos de gênero e estudos de sexualidade, pergunto-me sobre os modos como os saberes antropológicos no campo acadêmico instituem ou não formas de embates metodológicos entre as abordagens voltadas para a diversidade cultural $e$ as abordagens voltadas para as relações de gênero $e$ direitos sexuais. Ou se o campo acadêmico brasileiro busca formas possíveis de pensar a articulação entre esses direitos. 
Nos últimos anos, o direito à diversidade cultural se constituiu em discurso globalizado e politizado. Na arena dos acordos internacionais, o direito à diversidade cultural tem se constituído em moeda de troca para arrefecer a intensificação das reivindicações de direitos individuais à igualdade de gênero $e$ acesso a direitos sexuais, sem que, no entanto, tenham se intensificado os direitos coletivos ou comunitários dos povos indígenas. A diversidade cultural tem sido reivindicada especialmente por estados nações onde os interditos da divisão sexual e dos lugares das mulheres são postos não somente como regulados pelos costumes tradicionais e orais, mas sim por leis seculares e códigos religiosos.

Ao contrastar o campo acadêmico de estudos antropológicos de gênero e sexualidade no Brasil com o campo acadêmico estadunidense, concluo que tanto lá como aqui estão sendo produzidos investimentos $e$ inovações no pensar antropológico pela contínua produção de interfaces entre dispositivos teóricos analíticos, estudos empíricos e posicionamentos políticos sobre os processos de acessos a direitos individuais e coletivos. Contudo, lá e aqui, a irrupção da diversidade cultural no discurso globalizado tende a intensificar a produção de enfrentamentos de posições possivelmente antagônicas entre estudos que privilegiam a noção da "unidade cultural" com efeitos que podem frear a intensificação dos direitos à diversidade e à igualdade política entre gêneros.

\section{Da naturalização biológica da diferença sexual à construção social dos gêneros}

Antes do feminismo dos anos setenta, a diferença de gênero era a diferença de sexo posta no biológico; era a diferença percebida como inferioridade do sexo feminino ou como complementaridade dos sexos na divisão sexual do trabalho. Se a Antropologia e as Ciências Sociais não deixavam de ver, já antes da eclosão dos feminismos da "segunda onda" da segunda metade do século passado, que havia uma construção social dos 
papéis e uma construção simbólica do que seria a diferença de sexo, não questionavam sobre a sua própria aderência a uma prévia fundação biológica da diferença de sexo, produzindo assim uma naturalização da diferença de sexo de segundo grau - dessa vez, feita e reafirmada pelo mundo acadêmico.

Nos anos sessenta e setenta, especialmente com o impacto do feminismo inicial nos Estados Unidos, a reivindicação da igualdade é feita em nome das mulheres, construindo-se assim a ideia força de que o lugar das mulheres na sociedade era decorrente das relações sociais e que poderia e deveria ser mudado, não se devendo seu lugar a um determinismo biológico.

O Movimento pela Liberação das Mulheres na França, nos anos setenta, dá origem ao debate entre duas concepções: o feminismo igualitarista e o feminismo diferencialista. O feminismo igualitarista foi desenvolvido teoricamente pelas feministas no campo acadêmico das disciplinas de História, Sociologia $e$ Antropologia. Propugnava a igualdade de gênero e considerava todas as diferenças produções sociais e culturais em processo, portanto transformáveis. Mas o feminismo diferencialista, embora retirando a diferença sexual da fundação biológica determinante, repõe a diferença de sexo na dimensão do cultural e do simbólico, como uma diferença essencial, mas universal, em que o feminino não é visto como inferior, mas como diferente. ${ }^{1}$ Reivindica-se o mesmo valor de igualdade política para homens $e$ mulheres $e$ reivindica-se que a diferença simbólica ou de estilo seja igualmente valorizada e faça parte igual naquilo que seria o humano.

De um ponto de vista acadêmico compatível com os supostos de teorias psicanalíticas lacanianas e com algumas perspectivas analíticas literárias, entendia-se que se estruturam o feminino e o masculino distintamente no simbólico, cabendo aos homens concretos $e$ às mulheres concretas se distribuírem por essas duas estruturas, obedecendo, ou não, à tendência dominante de os homens biológicos se dirigirem ao masculino $e$

${ }^{1}$ De forma mais profunda e a partir de pesquisas feitas sobre os feminismos franceses, tratei desse tema em Machado, 1994 e 1997. 
de as mulheres biológicas, respectivamente ao feminino. Revelavase assim, de uma outra maneira, as variações possíveis em relação à adequação entre sexo masculino e feminino às estruturas simbólicas do masculino ou do feminino, e, ao mesmo tempo, a possibilidade de transgressões tanto a um quanto a outro.

$\mathrm{O}$ feminismo brasileiro responde fortemente à ideia da reivindicação da igualdade. Igualdade política e direitos iguais diante da sociedade e do Estado. Diferentemente do que ocorreu na França, o caráter ou qualidade da "natureza" da diferença entre mulheres e homens não se constituiu em tema de debate com alguma relevância na movimentação militante, embora tenha produzido alguns debates no campo teórico feminista. A preeminência da reivindicação da igualdade política tornou menos importante o debate entre identidade e diferença. A construção de uma categoria de mulheres pelo feminismo brasileiro se deu na dimensão política pela adesão à luta pela democratização, pela adesão ao combate à desigualdade de classes e pela proposta de direitos iguais entre homens e mulheres. Uma identidade política de reivindicação das mulheres foi construída e debatida. Se havia ou não uma identidade abstrata entre todas as mulheres ou se tal identidade era suficientemente flexível para abrigar a diversidade entre elas, por classes, raças ou orientação sexual, o debate não foi posto expressamente no cenário político. Era como se tanto houvesse uma identificação de situações e posições sociais entre as mulheres que possibilitasse uma identificação política, como abrangesse a diversidade entre elas. Buscava-se construir reivindicações comuns diante da sociedade e do Estado, por uma cidadania plena na esfera pública e privada.

Ao se afirmarem os estudos das relações de gênero, em substituição aos "Estudos de Mulheres", advindos dos campos acadêmicos norte-americano e inglês, a partir dos anos oitenta, passa-se a estar diante da afirmação compartilhada da ruptura radical entre a noção biológica de sexo e a noção social de gênero, de sua construção cultural e da afirmação do privilégio metodológico das relações de gênero, sobre qualquer substancialidade das categorias de mulher $e$ homem ou de 
feminino e masculino. É clássica na Antropologia britânica a inscrição, em 1980, do conceito de gênero por MacCormack $e$ Strathern relativa a contextos culturais distintos, em sua coletânea intitulada: Nature, Culture and Gender. Afirma-se, ao mesmo tempo, a transversalidade de gênero, isto é, o entendimento de que a construção social de gênero perpassa as mais diferentes áreas do social e se institui diferentemente em contextos culturais diversos, constituindo-se tanto internamente a saberes disciplinares como em saberes interdisciplinares. Para a posição paradigmática dos estudos de gênero é ainda fundamental a afirmação de que a análise das relações sociais e dos processos sociais, somente se faz quando se leva em conta as posições distintas dos sujeitos segundo o gênero, interseccionado com classe e raça/etnia, nas mais diferentes sociedades e contextos. Já o afirmava nesses termos: Gênero como paradigma (Machado, 1998).

\section{As construções das categorias múltiplas de gênero $e$ sexualidade $e$ as identificações políticas por alianças. Gêneros sem essências.}

Carrara e Simões (2007) referem-se à emergência dos movimentos homossexuais masculinos no Brasil na virada dos anos setenta aos oitenta. Referem-se com pertinência ao estudo de Edward MacRae (1990),

em seu trabalho sobre o grupo Somos/SP, o primeiro movimento homossexual brasileiro esteve também profundamente dilacerado quanto a se constituir ou não em torno de uma identidade homossexual.(...) Conforme aponta MacRae, o dilema entre "ser" ou "estar" homossexual foi uma das causas para a fragmentação do grupo Somos/SP (Id. ib.:59). Se inicialmente o grupo "partia do princípio de que a humanidade estaria dividida em heterossexuais $e$ homossexuais (e talvez alguns bissexuais)" (Id.ib.:40), acabaria por incorporar posições mais 'relativistas', como as que eram mantidas pelo próprio pesquisador e por alguns militantes (Carrara e Simões, 2007:6). 
Os movimentos homossexuais iniciais se defrontam assim com a ambiguidade da construção identitária: de um lado produzir identidade política positiva para enfrentar os interditos das fronteiras hegemonicamente hierárquicas entre heterossexual $e$ homossexual e, de outro, apontar e criticar a arbitrariedade da construção social hierárquica das fronteiras $e$ seus constrangimentos sobre a sexualidade.

Se a construção identitária das múltiplas formas de sexualidade foi tão importante $e^{2}$ para a demanda dos direitos à sexualidade nos movimentos LGBT, $e$ ainda que essas identidades se construíssem não somente como identidade política, mas como identidade de estilo de vida, performatividade e subjetivação em torno da "ideia de se assumir", segundo Carrara e Simões (2007), houve sempre no interior da movimentação no Brasil, uma simultânea relativização e crítica às construções identitárias como verdades inflexíveis. Muito antes da movimentação queer se instituir se contrapondo aberta e expressamente contra qualquer forma de produção identitária, sempre esteve presente nas movimentações brasileiras LGBT não só a proliferação de identidades como a crítica à imposição das identidades fixas e ao constrangimento social e político do estabelecimento de fronteiras entre a heterossexualidade legítima $e$ as sexualidades consideradas outras.

A movimentação LGBT tanto critica as identidades heterossexuais, como critica a imposição social de marcar as fronteiras. Com certeza é a movimentação queer que vem criticar expressamente todas as movimentações que buscam a afirmação de identidades sexuais. Para o antropólogo português Miguel Vale

é certo que o termo (queer) pode ser usado para descrever uma população aberta, cujas características partilhadas não são a identidade mas um posicionamento anti-normativo em relação à sexualidade (Vale de Almeida, 2003:61).

2 Ver a análise de Facchini (2005) sobre a produção das identidades coletivas no plural durante as movimentações dos anos noventa. 
$\mathrm{Na}$ concepção hodierna dos estudos de gênero e de sexualidade na antropologia no Brasil, há um enredamento $e$ articulação, apontando para o entendimento de que as fronteiras de gênero ultrapassam de longe quaisquer diferenças entre homens e mulheres, entre heterossexuais e homossexuais. Hoje se fala na produção cultural de diversos gêneros. Ao se pensar na constituição de gênero, a questão da sexualidade, mais do que simplesmente sexo, entra fortemente através das opções ou das orientações de sexualidade. Permite que o gênero seja e abarque, como diz a filósofa americana Judith Butler (1990), uma proliferação de gêneros, homens e mulheres, heterossexuais $e$ homossexuais, lésbicas, gays, travestis, transexuais, transgêneros e várias outras categorias.

No campo atual das conceituações teóricas e dos estudos etnográficos, a questão de gênero implica não só o modo pelo qual "eu/ele" me constituo como estilo feminino, masculino, como "eu/ele" me visto, como "eu/ele" penso etc., mas também implica em determinadas formas de sexualidade que se exercem. Hoje, estamos longe da ideia de que haja uma diferença eterna entre homens e mulheres, biologicamente assentada e simbolicamente reproduzida. A igualdade politicamente é que é importante. $\mathrm{O}$ fundamental é que se tenha a capacidade de valorizar politicamente, da mesma forma, todas as nomenclaturas possíveis de gênero da sociedade atual, todas as escolhas sexuais e todos os estilos de estética e modo de vida. É por isso que hoje tanto se fala e se exige, ao mesmo tempo, respeito à diversidade e à igualdade. A busca da igualdade não é a busca da identidade única, é a busca da igualdade política de direitos e do respeito à diversidade de estilos de vida, de estilos de sexualidade, de exercícios de opções, enfim, da diversidade de perfis emocionais, estilos $e$ identidades sempre em processo de fluidez $e$ instabilidade.

Hoje o campo acadêmico dos estudos de gênero $e$ sexualidade tornou mais complexa a noção de gênero. Por quê?? Porque sobre o gênero agora se tem uma grande certeza: não há consenso nenhum, nem essência nenhuma sobre o que é masculino e o que é feminino. O conceito de gênero complica, 
pois ele não mais admite dizer o que é o masculino, o que é o feminino, o que é o ser lésbica, o que é o ser gay. Não se define nenhum dos gêneros nem quantos são; os estudos de gênero afirmam que há uma proliferação de formas de ser e de se construir. Se há um consenso hoje nos estudos de gênero é que não há uma constância da definição do que é masculino, do que é feminino, do que é heterossexual e do que é homossexual. São construções sociais e culturais mutáveis, não determinadas pela fundação biológica ou pelo determinismo cultural, pois vivenciadas por investimentos subjetivos distintos com agencialidades diversas em práticas relacionais inseridas em situações de poder cambiantes.

Não se afirma aqui que no interior dos estudos de sexualidade e de gênero, não haja diferenças teóricas sobre o uso do conceito de identidade de gênero ou de identidades sexuais como fixas e quase determinadas culturalmente ou mesmo que não haja teorizações identitárias que busquem razões biológicas ou psicológicas, ou, ao contrário, se instituam como a inversão do estigma patológico atribuído pelos discursos médicos aos homossexuais. Grupos de estudo ou grupos de debates de antropólogos em congressos e seminários nas últimas duas décadas, contudo, tanto se encontram quanto se constituem separadamente em estudos de sexualidade e em estudos de gênero, marcando ora suas proximidades de perspectivas, ora a afirmação das fronteiras identitárias, ora sua desmarcação. Contudo, na e pela circulação intensa e tensa dos usos distintos das noções de gênero e sexualidade, sobressai e se consolida a noção de polimorfia e polifonia de gêneros em processo, gêneros sem fundações essenciais, gêneros instáveis, gêneros, que, no entanto, são submetidos a interditos e constrangimentos cristalizados e extremamente hierárquicos.

Judith Butler em Undoing Gender (2004) refere-se ao seu primeiro livro (GenderTrouble, 1990) e afirma que lá, ela fora absolutamente crítica ao uso pelo feminismo da categoria de mulheres, porque a categoria das mulheres não daria lugar à diversidade das mulheres, especialmente das mulheres lésbicas. 
Como as mulheres eram pensadas pelo senso comum abstratamente como heteronormativas, $e$ hegemonicamente, como brancas, a categoria de mulher poderia ser impeditiva de pensar o que eram as mulheres plurais e o que eram as mulheres homossexuais. Em Undoing Gender reconhece que a categoria mulheres possibilitou a politização da causa e a produção de alianças. Se não se acionassem questões identitárias, dificilmente se politizaria a questão das mulheres, ou a questão dos direitos da diversidade das identidades homossexuais. Mas alerta para que nenhuma categoria identitária possa ser eternizada ou não admitir diversidades.

Ao se pensar o conceito de gênero como construção cultural transformável, em termos acadêmicos antropológicos, torna-se claro que não há identidades, mas identificações em processo, jamais identidades eternas e uniformatadas. As mulheres no plural $e$ na diversidade, ao se reconhecerem duplamente nessa forma, podem construir alianças em termos de afinidade $e$ de identificação em processo que podem ser fecundas e produtivas em favor da igualdade de gênero e em favor dos direitos à diversidade sexual e em favor de um mundo misto de homens $e$ mulheres, heterossexuais e homossexuais com maior igualdade política. Da mesma forma, as distintas formas de sexualidade vivenciadas pelos seus diversos segmentos autonomeados, podem construir alianças em termos de afinidade e reivindicações políticas.

No meu entender, além da produção de debates sobre o peso das identidades ou das identificações nos estudos de gênero e de sexualidade, cada vez mais a circulação dos debates no campo acadêmico aponta para a passagem dos estudos das classificações identitárias para o estudo das práticas e dos comportamentos no interior das relações de poder, buscando ultrapassar as posições das mulheres ou das lésbicas ou dos gays ou dos transexuais, com o aprofundamento das vivências subjetivas com agencialidades diversas. A teorização de Deleuze (1983) apresenta pistas metodológicas para repensar o estatuto das classificações nos saberes antropológicos e, no meu entender, também nos saberes das relações de gênero e sexualidade. Propõe 
que as classificações não sejam entendidas como a verdade da ordenação das coisas por terem as coisas algo em comum, mas sim como formas e processos de os sujeitos sociais se classificarem sempre de forma incompleta $e$, nem sempre num contínuo considerado analiticamente como coerente.

\section{Inflexões e contrastes: direitos à diversidade cultural e direitos à diversidade sexual $e$ igualdade de gênero}

São três os pontos de inflexão principais que, no meu entender, tendem a diferenciar os estudos antropológicos que se situam no diálogo com os movimentos sociais feministas e de sexualidade e os estudos antropológicos que não consideram tal diálogo útil, adequado ou pertinente teoricamente, pois enfatizam a unidade de sentido de uma cultura, de um povo, de um grupo, de uma comunidade.

Um dos ensinamentos metodológicos, que hoje posso chamar já de "longa duração" das teóricas feministas, considerando-se sua produção relativamente consistente desde os anos oitenta, parece-me o primeiro ponto de inflexão que diferencia as posições entre os estudos antropológicos que reconhecem a dívida com os movimentos sociais feministas e de sexualidade e os estudos antropológicos que não reconhecem a relevância de tal diálogo.

Os saberes feministas apontam o princípio metodológico da consideração dos saberes situados dos pesquisadores e dos saberes dos sujeitos em foco, a partir de suas posições no contexto interacional e de relações de poder ou hierarquia (Harding, 1991, 1993 e 2004 e Code, 1993).

O primeiro ponto de inflexão é a posição paradigmática dos estudos feministas de gênero presentes também nos estudos de sexualidade: a análise das relações sociais e dos processos sociais nos mais diferentes contextos culturais capaz de não naturalizar a diferença sexual, somente se faz quando se levam em conta as posições distintas dos sujeitos segundo o gênero e sexualidade, interseccionados com classe e raça/etnia. No início dos estudos 
feministas, havia uma predominância das propostas de acentuar as operações de poder heterossexual masculino ou institucional $e$ as formas de imposição de subordinação e, por outro lado, as formas de resistência das mulheres.

$\mathrm{Na}$ continuidade das pesquisas feministas, as experiências das mulheres foram trazidas em formas variadas e diversas, ganhando espaço nos últimos anos, o recurso à noção de agencialidade, seguindo em grande parte as incursões da antropóloga britânica Strathern (1988) sobre a noção de agência e socialidade.

A antropóloga americana Mahmood (2005) afirma, seguindo Strathern (1988), e insiste que a ideia de agência não pode ser confundida com o princípio da oposição ou com a noção de resistência versus acomodação ou subordinação. Propõe que a perspectiva feminista dos estudos de gênero possa ir além do binômio resistência ou subordinação. Que se pergunte sobre os objetivos das ações, e dos seus porquês. Embora, no meu entender, deixe de se perguntar sobre os efeitos conservadores da posição subordinada de mulheres no Egito que, ao entrarem nos movimentos pietistas, buscam formas de autocultivação moral de constituição de subjetividades devotas, Mahmmod afirma a capacidade de agência das mulheres de forma ineludivel. As ações pietistas são por elas escolhidas para se transformarem em pessoas mais devotas e mais prestigiadas e menos dependentes de seus cônjuges e mais prestigiadas diante dos valores societários. Embora o movimento feminino do pietismo se distancie das propostas feministas seculares presentes no Egito, Mahmood atribui, analogicamente, qualidades de um novo feminismo ao movimento feminino pietista.

A antropóloga Adriana Piscitelli (2013) é uma das pesquisadoras que destaca a importância da noção de agência, termo que identifica com autonomia e livre escolha $e$ não com a imagem da mulher vítima traficada. Sua pesquisa focaliza mulheres que escolhem o trânsito internacional e a migração para exercerem a atividade de prostituição buscando rendimentos $e$ proteção social individual e familiar, sem deixar de apontar os 
constrangimentos que sofrem. A psicóloga feminista brasileira Kátia Guimaraes (2005) não utiliza o conceito de agência, mas sim o da subjetivação da identidade estigmatizada tal como vivenciada pelas prostitutas que entrevista. Ao mesmo tempo, apresenta a forma concomitante em que ressignificam o estigma social que lhes é imputado de vender o corpo. Cita uma das falas das entrevistadas:

eu acho que essa coisa de dizer que a gente vende o corpo é uma bobagem. Meu corpo está aqui comigo. E cuido muito bem dele. A gente está aqui para vender fantasia, ilusão (Guimarães; Merchán-Hamann, 2005:533).

Se Adriana Piscitelli revisita as propostas políticas do combate ao tráfico de pessoas como forma de proteger direitos das mulheres, apontando suas inconsistências a partir da revelação das formas vivenciadas pelas prostitutas em trânsito, a antropóloga feminista Heloisa Buarque de Almeida (2002), que analisa a mídia televisiva da telenovela como melodrama comercial, também afirma, ao final, que sua análise supõe um posicionamento crítico e político:

Isso não significa que os pesquisadores $e$ acadêmicos devam concordar com essas construções culturais, ou considerar que elas são capazes de explicar as desigualdades de gênero. Mas certamente cabe a nós, antropólogas e pesquisadoras da sociedade e da cultura, destacar e perceber como funcionam certas lógicas $e$ construções culturais nas sociedades que estudamos $e$, no caso deste artigo, destacar aqui o poder relativo da mídia na construção do gênero (Almeida, 2002:194).

De uma forma mais premente ou distante, as questões que envolvem direitos e conflitualidades sempre estão presentes $e$ norteiam as perspectivas analíticas dos autores $e$ autoras. A diversidade cultural é suposta e apresentada, mas não se apagam as posições diferenciadas nas relações de gênero, assim como não 
se apagam posições diferenciadas entre análises das pesquisadoras frente às tendências dominantes das articulações feministas e das configurações das políticas sociais para as mulheres.

Os estudos de gênero e sexualidade na antropologia das últimas décadas têm enfatizado a prática e os atos no processo relacional, a análise contextual do self, da ação pessoal, da agencialidade, da subjetivação ${ }^{3}$, da corporalidade e da sexualidade, das relações de gênero na divisão do trabalho, dos usos diferenciados do tempo nas relações domésticas segundo as relações de gênero, das relações de poder e dos investimentos subjetivos que se traduzem em sentimentos, emoções e afetos, e a análise das formas institucionais das narrativas de gênero e da sexualidade tal como aparecem nas tendências da mídia. Seguindo os eixos temáticos centrais dos movimentos sociais, estudos acadêmicos antropológicos e interdisciplinares acompanham $e$ analisam no cenário político os debates sobre legislações e processos jurídicos referentes aos direitos reivindicados como parcerias civis e união estável entre homossexuais, direitos sexuais, legislações referentes ao enfrentamento a violências de gênero e a "crimes de ódio" contra homossexuais e sobre as políticas públicas que envolvem os direitos sexuais. O trabalho de Vianna e Lacerda (2004) faz, por exemplo, o levantamento e a análise dos Direitos e Políticas Sexuais no Brasil. Seguindo ainda os eixos temáticos centrais dos movimentos sociais, desenvolvem-se estudos sobre os debates em torno dos direitos reivindicados de descriminalização do aborto, dos direitos a saúde, dos direitos reprodutivos, e sobre os debates sobre paridade de gênero na reforma política, dentre outros. Incursões sobre o entendimento das concepções e relações de gênero nas sociedades indígenas ganham espaço ainda que incipiente nos estudos etnológicos de antropólogas brasileiras que dialogam com os estudos de gênero, assim como há estudos sobre

\footnotetext{
3 Ver aqui as contribuições estimulantes de Henrietta Moore (2007) para articular as noções de agência e subjetivação.
} 
a movimentação das mulheres indígenas em torno dos direitos à saúde e ao enfrentamento da violência.

O trabalho de Grossi, Minella e Mendes (2006) faz um levantamento das questões presentes no campo acadêmico sobre a temática feminista candente da violência de gênero, chegando a computar 286 trabalhos de pesquisas realizadas em universidades, entre 1975 e 2005, sobre violência contra as mulheres abrangendo teses de doutoramento, dissertações de mestrado, monografias de graduação, e formas variadas de relatórios de pesquisa e monografias de especialização -, sem que tenham sido contabilizados os trabalhos publicados em revistas científicas e em livros e coletâneas. Sua distribuição se concentra em algumas universidades, mas se realiza em todas as regiões brasileiras, demonstrando o quanto os saberes disciplinares acadêmicos de estudos de gênero se articulam com a movimentação feminista no Brasil e com as reivindicações de direitos.

As interfaces produzidas entre movimentos sociais por direitos de gênero e de sexualidade e a produção acadêmica são desafiantes. Os estudos de gênero e de sexualidade, ao dialogarem e contribuírem para a produção do conhecimento, revelam como a produção do conhecimento é produção enredada de dilemas de conhecimento disciplinar e de dilemas de percepção política.

O segundo ponto de inflexão é a forma de tratar metodologicamente da diversidade cultural, entendida como diversidade cultural societária. Enquanto os estudos feministas de gênero $e$ os estudos de sexualidade reconhecem a diversidade $e$ heterogeneidade entre códigos culturais, mas entendem que o seu compartilhamento não significa o apagamento das posições diferenciadas segundo as posições e vivências das relações sociais de gênero e sexualidade, classe e etnia/raça, os estudos antropológicos que não destacam a relevância das relações de gênero e sexualidade, tendem a considerar a diversidade cultural da alteridade, como intransponível e a cultura como uniformatada, como se estivesse fundada no consenso ou em equilíbrios pendulares. Assim, quando se referem a culturas de 
gênero, é como se aquele contexto sociocultural tivesse um compartilhamento homogêneo, somente um ponto de vista $e$ somente uma idêntica forma de vivenciar a sua posição nas relações da diferença sexual e de gênero. Esse ponto de inflexão se assenta na oposição entre o entendimento de uma cultura que se supõe fundada em socialidade vista a priori como prevendo consenso e homogeneidade versus uma cultura fundada em socialidade pressuposta como implicando não somente relações consensuais como relações conflitantes e em disputa.

O terceiro ponto de inflexão está intimamente associado ao segundo, pois é a forma de o autor/a se situar diante dos sujeitos pesquisados e diante de seu tema, tratando ou não de se decidir por metodologias que o levem à adesão aos direitos coletivos ou aos direitos individuais, ou ainda à adesão à dupla consideração. Os direitos coletivos estão vinculados ao direito à diversidade cultural $^{4}$ do grupo ou povo como um todo e os direitos individuais estão vinculados ao cuidado de implicar e focar seu trabalho em relação aos direitos pela igualdade de gênero ou pela diversidade sexual. Além de privilegiar um ou outro direito, ou acreditar na sua combinação ou articulação possível, há diferenças na forma de o pesquisador se perceber ou não como dentro de um dilema em que a sua metodologia é percebida como conhecimento objetivo, como se não implicasse um posicionamento político, ainda que não militante.

Dado que os saberes antropológicos contemporâneos, sem dúvida, contribuíram para a conceitualização e defesa dos direitos coletivos e comunitários à diversidade cultural, muito dos pesquisadores que se dedicam a pensar práticas culturais em socialidades da alteridade, ou seja, não modernas, não dão relevância a seu posicionamento político como posicionamento que possa ser percebido como interveniente, a partir de seu lugar de sujeito pesquisador. É como se sua metodologia fosse objetiva

\footnotetext{
${ }^{4}$ Ver, nesse sentido, em Ribeiro (2007), como o discurso da diversidade cultural se constitui como um discurso global, guardando, no entanto, efeitos distintos nos âmbitos locais.
} 
por si mesma, baseada nos pressupostos modernos do relativismo cultural e da metodologia que exige o ver, perceber e respeitar a diversidade cultural. Outros optam pela perspectiva da análise que privilegia os direitos culturais comunitários ou coletivos e outros pela articulação das ressignificações necessárias para englobar e cuidar tanto do que se dirá sobre os direitos coletivos, como do que se dirá dos direitos de gênero e sexualidade. Outros ainda optam pela atenção exclusiva aos direitos humanos individuais, sem buscar articulações possíveis entre direitos coletivos $e$ direitos individuais.

$\mathrm{Na}$ sua atual conceituação, de acordo com a Declaração Universal sobre a Diversidade Cultural adotada pela Conferência Geral da Organização das Nações Unidas para a Educação, Ciência e Cultura na sua 31. a sessão, a 2 de Novembro de 2001, no seu artigo 4, afirma-se que:

a defesa da diversidade cultural é um imperativo ético, indissociável do respeito pelos direitos humanos. Implica um compromisso para com os direitos humanos $e$ liberdades fundamentais, em particular os direitos das pessoas pertencentes a minorias e dos povos indígenas.

Acrescenta-se, no entanto, que: "Ninguém pode invocar a diversidade cultural para justificar a violação dos direitos humanos garantidos pelo direito internacional, nem para restringir o seu âmbito".

Contudo, no seu preâmbulo, o entendimento de cultura é assim expresso:

a cultura deve ser vista como um conjunto de características espirituais, materiais, intelectuais e emocionais diferenciadoras de uma sociedade ou de um grupo social, $e$ que compreende, para além da arte e da literatura, os estilos de vida, as formas de viver em conjunto, os sistemas de valores, as tradições e as convicções. 
Essa definição de cultura, com certeza, tende a reafirmar a convicção de muitos antropólogos de que a cultura uniformata as convicções e os sistemas de valores.

Esse me parece o pressuposto do entendimento de Cardoso de Oliveira (2005) e de Simião (2002) ao se referirem a um suposto consenso sobre as vivências recíprocas do "bater de homens em mulheres" $e$ do "bater-se entre homens e mulheres" no Timor Leste. Retomo aqui em parte considerações que fiz em Machado (2010). Supõem os autores que se a prática de bater tem uma justificativa moral deveria ser vivenciada igualmente tanto pelos homens que batiam para corrigirem suas mulheres como pelas mulheres que eram batidas e corrigidas. Não consideraram necessário distinguir as posições de mulheres e de homens diante dessas relações desiguais, pois as "práticas eram aceitas" na comunidade. Simião autoriza a fala de um entrevistado masculino:

Um timorense, técnico de impressão em uma gráfica local,
estava casado havia onze anos e sempre batera em sua
mulher. Ela sempre sentira a dor física, mas nunca se
incomodara com isso. Até o momento em que pediu a
separação. O marido não compreendeu. Não via motivos,
afinal aquele vinha sendo o padrão de conduta do seu
relacionamento há mais de uma década, e nunca a
incomodara. (...) O marido convenceu-se de que os
estrangeiros estavam "colocando coisas" na cabeça de sua
mulher (Simião, 2002:94).

Logo mais adiante, Simião na qualidade de pesquisador $e$ autor afirma: "Certamente de algum modo, é isso que aconteceu". Nas palavras de Cardoso: "Enquanto o bater tinha uma justificativa moral e o sofrimento da vítima era essencialmente físico, a prática era aceita." E conclui que não havia violência porque não havia insulto. Tudo é apresentado como se no ato de bater não houvesse desvalorização (insulto) no âmago das relações interpessoais de gênero, nas quais um sujeito social bate $e$ outro sofre o ser batida e o ser corrigida e assim é desvalorizada e desconsiderada (ainda que esse ato seja 
percebido pelas normatizações comunitárias como "aceito", ou seja, como "normal").

$\mathrm{O}$ reconhecimento do valor do relativismo cultural face à diversidade cultural pode estar obscurecendo o que dizem as estudiosas das relações de gênero: que as práticas culturais "aceitas" não são lugar de consenso, mas são lugares de disputa $e$ de conflitualidade no seio mesmo das relações de gênero esperadas e compartilhadas. Nesse tipo de relações não se compartilha consentimento ou consenso, mas sim compartilhamse as expectativas de que se sentem instados a se posicionarem, impondo, cedendo, ou enfrentando os investimentos subjetivos para alcançar a desvalorização e a obediência do outro frente ao qual disputa.

De forma distinta $e$ por caminhos quase opostos, o sociólogo e antropólogo Bourdieu (1990:8) tende a refazer uma noção uniformatada de cultura, pela forma em que toma o conceito de relações de gênero de poderes desiguais e o engessa ao transformá-lo em dominação masculina, sem adentrar nos meandros das relações em disputa ao redor e no âmago da dominação. Analisando as práticas kabile já estudadas anteriormente (Bourdieu, 1972), entende que o gênero feminino dominado, na prática e no interior das relações sociais de gênero, não dispõe de instrumentos para pensar, ou de instrumentos para se afastar do impensado cultural que não sejam os habitus incorporados no contexto da dominação masculina tanto na dimensão corporal como nas atitudes e expectativas. As disposições dos dominados são aquilo que têm em comum com os dominadores, ou seja, o gênero feminino dominado realiza a forma incorporada da relação de dominação. A ideia de dominação masculina, tal como formulada por Bourdieu, incide no risco de naturalizá-la, pois o autor a ela se refere como quase inerente à ordem social, como prática e regra, quando, ao contrário, do olhar paradigmático da metodologia feminista de gênero, a dominação masculina deve ser lida como se dando em processo relacional, em que as posições e os olhares de mulheres $e$ de homens sempre as percebem diferentemente, ainda que 
compartilhem os mesmos códigos culturais, pois diferem suas posições relacionais.

O pensamento antropológico feminista dos estudos de gênero e o pensamento dos teóricos antropólogos que dialogam com a movimentação LGBT são duplamente tributários, tanto das concepções históricas e mais recentes dos direitos à diversidade cultural como dos direitos à igualdade de gênero e diversidade sexual. No artigo 38 da Declaração de Viena (1993), a defesa dos direitos à diversidade cultural não pode prevalecer se as práticas tradicionais ou costumeiras forem contrárias aos direitos humanos das mulheres na vida pública e na vida privada. Para os estudos feministas e de sexualidade, são os direitos humanos individuais das mulheres e de todos os gêneros, que devem ser protegidos diante de práticas culturais contrárias, e os direitos coletivos devem ser sempre preservados, desde quando não forem contrários ao que foi acordado como direitos individuais. De forma não tão explícita, a Conferência Internacional sobre População e Desenvolvimento no Cairo (1994) reconheceu e afirmou a expressão dos direitos sexuais e dos direitos reprodutivos.

Já afirmei em Machado (2010:90) que

a defesa simultânea de direitos das mulheres e de direitos à diversidade cultural de suas comunidades e povos, implica sempre um tenso processo de ressignificação cultural (Soares, 2001; An-Naím, 1991; Wilson, 1997; Segato, 2004; IfnaVrede, 2001) num mundo cada vez mais globalizado inserido numa cosmopolítica (Ribeiro, 2005).

Politicamente, nesse sentido, as(os) antropólogas feministas entendem ser possível as simultâneas, ainda que tensa, defesa dos direitos das mulheres e defesa dos direitos à diversidade cultural , com a restrição de que não devam ser defendidas como direitos à diversidade cultural, as práticas costumeiras que agridam os direitos das mulheres. Os Movimentos de Mulheres Indígenas no Brasil vêm se articulando recentemente não só em prol dos direitos indígenas, mas com ressignificações culturais que 
destacam e afirmam os direitos das mulheres indígenas (conforme análises de Machado, 2009b e Segato, 2004).

\section{Contrastes e Deslocamentos: entre o campo acadêmico de estudos feministas estadunidense e brasileiro}

Nos campos intelectuais de estudos feministas e de gênero, brasileiro e latino-americano (Segato, 2004 e Machado, 2010), a crítica antropológica mais recente, pós-moderna e pósestruturalista ao universalismo, presente nos primórdios da linguagem dos direitos humanos e do feminismo, parece buscar as ressignificações, as ressonâncias, as interpretações e traduções para que a linguagem dos direitos humanos e do feminismo seja mantida. Busca resguardar, no que for possível, o respeito às diversidades culturais- retomando questões postas nos anos noventa por An-Na'im (1991) e Wilson (1997). Contrastivamente, o campo estadunidense me pareceu, a partir da minha experiência recente presencial como professora visitante e pesquisadora na Universidade de Columbia, em Nova York, nos anos de 2009 e 2010, abrigar uma distinta forma de lidar com a diversidade cultural. Aí, nesse nicho de contexto relacional, pareceu-me que é a linguagem dos direitos humanos $e$ a linguagem feminista que devem se ressignificar para manter o respeito à diversidade cultural.

$\mathrm{Na}$ minha experiência de relação com esse nicho, que é parte de um campo intelectual feminista estadunidense mais amplo, a crítica à linguagem dos direitos humanos como linguagem "ocidental" apareceu fortemente tanto na relação com os estudantes inscritos nos meus dois cursos de pós-graduação, como com estudantes presentes nos seminários, e entre pesquisadoras/es sêniores e juniores, seja na condição de palestrantes ou de público. Uma desconfiança consolidada em que o "ocidente" estaria impondo de "cima para baixo" a proposta da formulação dos direitos humanos, assim como, dos direitos humanos das mulheres. O principal eixo da crítica se centrava na forte fundamentação dos direitos humanos como direitos 
individuais e liberais. $\mathrm{O}$ individualismo era lido e entendido como característica do "ocidente" que estava sendo imposta a países e culturas "não ocidentais". A crítica ao "ocidentalismo" dos direitos humanos parecia, em grande parte, tomar o lugar de crítica não somente às "formas de implementação e de uso político pelos países ocidentais das exigências de acatamento aos direitos humanos" como forma imperial de negociar. Atingia também a formulação mesma de conteúdos substantivos dos acordos internacionais $e$ intergovernamentais realizados nas diversas instâncias, tratados e protocolos das Nações Unidas.

Palestras proferidas por Saba Mahmood, professora antropóloga da Universidade de Berkeley e por Lila Abu-Lughod, professora antropóloga da Columbia University, em forma de "conversação pública", na cidade de São Francisco, em 10 de fevereiro de 2009, e publicadas na internet (Abu-Lughod, Lila e Mahmood, Saba, 2009), permitem entender a transformação que se opera nas formas de abordar as questóes do combate à violência contra as mulheres.

Saba Mahmood critica o uso da administração Bush do sofrimento das mulheres na declaração de guerra contra o Afeganistão. Conclui que "é crucial entender que qualquer tentativa de trazer mudança para o bem-estar do povo de cima para baixo tem usualmente produzido um desastre".

Lila Abu-Lughod (2009) aponta a existência de mulheres islâmicas que se movimentam para os direitos das mulheres em seus países:

Há muitos esforços nos países muçulmanos para buscar como a "Convenção (das Nações Unidas) para a Eliminação de todas as formas de Discriminação contra as Mulheres" (CEDAW), a Sharia e a Lei islâmica, possam trabalhar em conjunto. Muitas mulheres educadas $e$ cosmopolitas muçulmanas estão abertas para uma espécie de "feminismo baseado na fé" (Abu-Lughod, Lila e Mahmood, Saba, 2009). 
Um desses movimentos é denominado "Mossawa", que significa "igualdade". O esforço é para repensar o que o Islá significa e defender uma forma mais esclarecida de interpretação, pois como "muçulmanas e cidadãs querem justiça na família". Outro é o movimento do Conselho Consultor das Mulheres Muçulmanas da Sociedade Americana para o Avanço das Mulheres Muçulmanas, que também propõe a reconciliação dos direitos das mulheres e da Sharia. Abu-Lughod entende que "nós devemos trabalhar a partir da tradição, trabalhar de dentro $e$ transformar".

Se Mahmood propõe a atenção para a agência das mulheres que se movimentam no campo religioso, fora do contexto articulável com qualquer princípio individualista e de política identitária, Abu-Lughod estabelece empiricamente o que entende como um feminismo baseado na fé, um feminismo baseado em política identitária em nome de maior autonomia para as mulheres, mas que se organiza a partir da reinterpretação da tradição cultural religiosa, dentro do que for considerado possível e desejável. Aqui Abu-Lughod não se distancia em nada do debate feminista e acadêmico brasileiro de que é possível uma ressignificação dos direitos das mulheres advinda da articulação entre valores de tradições culturais não liberais e não seculares.

Por outro lado, apresenta sua distância, quando é acerbada na crítica ao modo como percebe a agenda internacional feminista referida à violência contra as mulheres muçulmanas. Considera essa agenda marcadamente "ocidental", depreciadora $e$ inferiorizadora do mundo islâmico.

Refere-se, entre outras, à "Campanha Global para acabar o Apedrejamento e o Assassinato de Mulheres", realizada em 2007 pelas Mulheres Vivendo sob a Lei Muçulmana (Women Living UnderMuslim Law). A Campanha justifica essa ação porque

é preciso combater a tendência de legitimação cultural $e$ religiosa da religiosa violência contra as mulheres" ${ }^{5}$. [Abu-

\footnotetext{
${ }^{5}$ O site da associação Women Living Under Muslim Laws está disponível em $<$ http://www.wluml.org/english/index.shtml. $>$
} 
Lughod critica] "...o aspecto restritivo da Campanha que combate apenas alguns tipos de violência contra as mulheres: a violência pelos regimes muçulmanos locais, pelos Islamitas e pelas famílias. Não combate todas as formas de violência contra as mulheres. (...) O que está faltando é a incrível violência contra as mulheres infringida pela guerra. (...) Onde está a campanha feminista para estas mulheres? Por matarem estas mulheres? Por matarem seus familiares amados? Por feri-las e ferir seus familiares amados? (...) Por que o apedrejamento das mulheres-que acontece em alguns lugares uma vez a cada muitos anos em uma parte do mundo - está na ordem do dia e não a violência infringida pela guerra? (Abu-Lughod, 2009).

Lughod propõe uma reinversão da hierarquia da pauta feminista contra a violência. Na agenda internacional foi estabelecida a afirmação englobante do combate à violência de gênero, na qual a violência contra as mulheres nos conflitos de guerra tem papel destacado, mas é subsumida à mensagem de que há uma forma de violência que atinge as mulheres em função de seu gênero. Abu-Lughod critica a excessiva ênfase na violência de gênero e propõe a ênfase política crítica contra a violência da guerra ocidental contra os países islâmicos que é, ao mesmo tempo, guerra de armas e imposição de discriminação cultural.

No mesmo tom, mas referindo-se à comparação entre os modos americanos de se tratar violência contra as mulheres nos Estados Unidos e nos países islâmicos, Saba Mahmood enfatiza criticamente a atribuição da característica cultural como causa e razão dos assassinatos das mulheres nos países muçulmanos, enquanto "em casa", nos Estados Unidos, se entende a violência doméstica como uma questão individual, patológica ou passional. Indaga "por que os 'assassinatos por honra' (honor killings) se tornaram um crime identificável enquanto a 'violência íntima', os chamados 'crimes passionais', não?"

Lembra "que são crimes comparáveis, mas um é associado com cultura e o outro com indivíduos, o que não faz nenhum sentido" (Mahmood, 2009). Contudo, não faz crítica à atribuição do 
caráter individual e passional dado aos crimes de assassinatos de mulheres, mas sim, faz somente críticas à atribuição do caráter cultural dados aos assassinatos de mulheres em nome da honra. Com certeza está criticando que a "cultura" é atribuída pelo senso comum aos outros e que a América não se entende como uma cultura específica, mas composta de "indivíduos livres". Mesmo assim, não critica a falta de reconhecimento da América como uma, entre outras diversidades culturais.

Nessa conversação pública de Mahmood e Abu-lughod foi enfatizado que a sua crítica à proposta feminista de combate aos "honor killings" (crimes em nome da honra) se baseia em que esse termo se constitui em uma forma "ocidental" de desconsideração das culturas dos países não ocidentais, em particular, países do leste e países islâmicos. Foi mostrada a íntima conexão entre a crítica "ocidental" ao uso da "burka" e aos "honor killings" e a utilização do governo Bush para justificar a guerra contra o Afeganistão, como uma forma de "salvar as mulheres afegãs" $e$ outorgar-lhes direitos.

Em lugar da ênfase ao combate aos "honor killings" do feminismo norte-americano hegemônico e internacional, as intelectuais feministas e pesquisadoras propõem a ênfase ao combate aos "warkillings", ou seja, dar visibilidade aos efeitos trágicos da guerra americana e ocidental contra as populações civis dos países islâmicos, especialmente, mulheres e crianças, que, além de serem diretamente atingidas, sofriam e viam seus maridos e filhos sofrerem e morrerem. Por que a mídia, o governo e as feministas tão pouca atenção davam aos sofrimentos impostos às mulheres pelas guerras, e somente falavam do "horror" da "cultura dos crimes de honra"? Enfatizar as mulheres de "outras culturas" como vítimas de violência impediria ainda a percepção da autonomia das mulheres dos países não ocidentais.

Deparava-me assim com um dilema e um problema. $\mathrm{O}$ meu deslocamento do contexto político brasileiro para o estadunidense parecia ter propiciado com mais clareza a percepção do deslocamento da pauta internacional da agenda feminista 
comparando-se o campo estadunidense e o campo brasileiro $e$ latino-americano.

No Brasil, faz-se muito mais facilmente nos meios feministas acadêmicos e militantes, a crítica à nomeação dos assassinatos de mulheres como crimes passionais, crimes íntimos ou patologias individuais e não se faz crítica à nomeação de seu caráter cultural, porque se o pensa transformável. Quando se usa a noção de cultura da violência ou se reconhece que a noção de "honra familiar relacional" (Machado, 2010) é um valor cultural enraizado, não pensamos que politicamente, estaríamos incorrendo numa depreciação de toda uma cultura nacional ou local. Insistimos as feministas e intelectuais que estamos diante de uma modalidade social relacional que devemos combater (ou que pode ser combatida), da noção de honra que devemos superar (ou que pode ser superada) sem que se instaure qualquer "vazio ou destruição cultural". Reconhecem as teóricas feministas as agências individuais nos atos de violência $e$ a inserção dessas "razões individuais" em regras sociais consolidadas porque simbólica, social e juridicamente foram e ainda são consideradas legítimas. Buscam a deslegitimação dos atos individuais de violência e sabem que necessitam buscar a deslegitimação cultural no seu sentido institucional. Caufield (2005), historiadora, faz um brilhante trabalho crítico à noção de defesa da honra como argumento jurídico exculpatório ou atenuante no decorrer das Ordenações Filipinas coloniais e dos códigos penais republicanos.

Teoricamente, a noção de relações de gênero, relações étnicas e relações raciais, fazem efeitos na capacidade de apontar as formas genderizadas de violências e suas articulações com as violências racializadas e diferenciadas segundo orientações sexuais que se realizam mundialmente entre as formas de violência contemporânea dos poderes da colonialidade e da póscolonialidade. Não nos parece caber assim utilizar o dualismo: individualistas ocidentais liberais versus outros membros de culturas totalizantes não liberais e não individualistas (aliás, se o fizéssemos, teríamos um problema, pois onde estaríamos "nós", já 
que, do ponto de vista norte-americano dificilmente somos consideradas pertencentes ao ocidente individualista liberal?)

Minha imersão no contexto político-cultural estadunidense me fez defrontar com a premência de parte da crítica de esquerda progressista interna norte-americana ter como foco a crítica aos modos imperiais norte-americanos. A linguagem dos direitos humanos das mulheres foi confundida como derivada da imposição ocidental. A prioridade da crítica política foi dada à defesa da diversidade cultural. Em segundo plano, o combate à desigualdade de gênero, desde que impulsionado pelas mulheres locais. Como se fosse possível, no mundo globalizado, uma certa "movimentação exclusiva" de caráter nacional. Há sempre algumas formas de enredamento das articulações feministas globais e locais.

Enfatizo os efeitos dos contextos políticos americanos nos debates feministas como efeitos "locais", em que o "local" é depreendido diretamente da reflexão sobre a posição hegemônica americana nas relações globais. O contexto político imperial dos Estados Unidos e o contexto político recente de guerra simbólica e por armas em relação aos países do leste, como Iraque, Afeganistão e Irã, propiciou e produziu uma enorme diferença nas posições de sujeitos feministas acadêmicos estadunidenses e nos seus debates internos $e$ internacionais. Entendo e considero relevante a percepção crítica das intelectuais ao uso $e$ manipulação dos direitos humanos em nome de poderes de Estado contra Estado. Sobre a Guerra contra o Afeganistão, por exemplo, muito foi dito em nome dos direitos das mulheres. Evidentemente fez efeitos positivos para os direitos das mulheres, mas foi um desastre em termos dos tormentos de uma guerra para homens, mulheres e crianças.

Pergunto-me, no entanto, por que as feministas $e$ as intelectuais acadêmicas dos estudos de gênero e de sexualidade não podemos fazer as duas críticas ao mesmo tempo? Denunciar as guerras devastadoras e ao mesmo tempo continuar a fazer a crítica ao apedrejamento de mulheres, aos direitos suprimidos de gays e lésbicas. Por quê? 
As organizações feministas nacionais e internacionais de base norte-americana mantêm a centralidade da condução da política internacional feminista de combate a todas as formas de violação dos direitos das mulheres em todo o mundo e nas mais diferentes culturas. Mas em centros de produção intelectual acadêmica de estudos feministas criaram-se espaços para a formulação crítica contra a agenda internacional sustentada pelas feministas americanas, em nome do respeito à diversidade cultural e em nome da crítica aos poderes imperiais dos Estados Unidos.

Butler (2004), fazendo a crítica ao pensamento ocidental contido na ideia de universalidade, não se atém fortemente ao dualismo ocidente e oriente, nem atribui um lugar secundário às lutas feministas, "queer" e homossexuais contra a violência. Busca alternativamente a ideia de uma procura da "commoness" de uma desejada "liveable life", entendida como uma vida vivível dignamente e sem violência. Conversando com Spivak (1995), propõe, insinua, alude a uma possibilidade de tornar a ideia de "liveable life", ainda muito ocidental, articulada ou substituída pela ideia não ocidental de uma "sacred life". O "novo feminismo" global $e$ transnacional que pudesse incorporar as mais diversas culturas e religiões parece fazer sentido também a partir das considerações de Butler.

Ao ler e ouvir presencialmente Butler nos Estados Unidos, perguntava-me como poderia assimilar suas novas considerações se, no Brasil, embora acostumada a respeitar a liberdade religiosa, cada vez mais me via na necessidade de combater qualquer relação privilegiada de uma religião com o poder de Estado, já que o caráter laico do Estado está sendo criticado por frentes $e$ lideranças políticas religiosas assentadas no Parlamento que imaginam serem as famílias, $e$ as posições tradicionais das mulheres nas famílias, os lugares de salvação da moralidade? ( $\mathrm{E}$ quanto sabemos das famílias como lugares de não direitos das mulheres...) Perguntava-me então: o que fazer diante das forças antifeministas por parte de institucionalizações religiosas e laicas conservadoras? 
A crítica americana contundente que emerge a partir de intelectuais antropólogas feministas à linguagem internacional dos direitos humanos parece se reverter numa quase naturalização ou desistência da possibilidade de conversação e de negociação plural pela instituição dos direitos pela igualdade de gênero $e$ direitos à diversidade de sexualidades. É como se a crítica se fizesse por considerar que os direitos humanos na linguagem das organizações internacionais das Nações Unidas, não fossem mais que imposições norte-americanas dos seus direitos individuais. Contudo, é fato que na atuação internacional bilateral dos Estados Unidos em relação aos estados nações está previsto que os direitos de homossexuais e de mulheres não atendidos podem ser moeda de troca para bloqueios econômicos e intervenções políticas.

$\mathrm{O}$ risco é esquecer que os tratados e declarações internacionais de direitos humanos não são o resultado das propostas de um Estado-nação norte-americano, mas o resultado, ainda que parcial, das propostas contínuas das lutas subalternas de mulheres, homossexuais e antirracistas de mundos não hegemônicos, como os latino-americanos, os asiáticos e os africanos, na elaboração, tradução e sustentação da noção de direitos humanos e da positividade dos efeitos das articulações e tratados acordados internacionalmente.

De outro lado, mais atenção crítica nos países latinoamericanos poderia ser dada pelas feministas e pelas pesquisadoras/es dos estudos de gênero e sexualidade na sua interface com os direitos humanos, aos modos de implementação da agenda internacional feminista que também se situa na complexidade da condensação de forças dos diferentes estados nações que operam não só por uma reciprocidade horizontal, mas também por imposições verticais de poder, ou ainda por novas formas de alianças entre poderes conservadores nas mais diferentes culturas e entre os países em distintos estados de desenvolvimento. 


\section{Referências bibliográficas}

ABU-LughOD, Lila e MAHMOOD, Saba. Gender, Islam and the West. Do Muslim Women want rights? February, 10, 2009. Disponível em: http://ies.berkeley.edu/ssrc/labulughodsmahmood.html. Acesso em: janeiro 2010, New York.

AlmEIDA, Heloisa Buarque de. Melodrama comercial: reflexões sobre a feminilização da telenovela. Cadernos Pagu (19), Campinas-SP, Núcleo de Estudos de Gênero-Pagu/Unicamp, 2002, pp.171-194.

AN-NA'IM, Abdullahi (ed.). Human Rights in Cross- Cultural Perspective: A quest for consensus. Philadelphia, Univ. of Pennsylvania Press, 1991

ASAD, Talal. Anthropology and the Colonial encounter. Atlantic Highlands, Humanity Press, 1973.

ASAD, Talal. Modern Power and the Reconfiguration of Religious Traditions. Standford Electronic Humanities Review, vol. 5 (1), 1996. Disponível em: http://www.stanford.edu/group/SHR/51/text/asad.html.

BOURDIEU, Pierre. Esquisse d'une Théorie de la Pratique Précedé de Trois. Etudes d'Ethnologie Kabyle. Genebra, Droz, 1972.

Bourdieu, Pierre. "La Domination Maculine". Actes de la Recherche en Sciences Sociales, Paris, nº 84, 1990, pp.2-31.

ButLER, Judith. Gender Trouble. Londres, Routledge,1990.

BUTLER, Judith. Undoing Gender. New York e Abington, Routledge, 2004.

CARDOSO de OliveIRA, Luís R. Direitos, Insulto e Cidadania. Existe violência sem agressão moral? Série Antropologia n 371, Brasilia, 2005.

CARRARA, Sérgio e Simoes, Júlio Assis. Sexualidade, cultura e política: a trajetória da identidade homossexual masculina na antropologia brasileira. CadernosPagu (28), Campinas-SP, Núcleo de Estudos de Gênero-Pagu/Unicamp, 2007. Disponível em: $<$ http://www.scielo.br/scielo.php?script=sci_arttext\&pid=S0104$83332007000100005 \& \operatorname{lng}=\mathrm{pt} \& \mathrm{nrm}=$ iso $>$.

CAUlfiElD, Suzan. Em Defesa da Honra. Campinas, Ed. UNICAMP, 2005. 
CODE, Lorraine. Taking Subjectivity into Account. In: AlCOFf e POTTER (edit.). Feminist Epistemologies. Ed. Routledge, New York and London, 1993, pp.15-48.

Deleuze, Gilles. Cinéma Cours 42 du 24.05.1983. Disponível em: http://www2.univ- paris8.fr/deleuze/article.php3?id_article $=244$.

FACCHINI, Regina. Sopa de letrinhas? Movimento homossexual e produção de identidades coletivas nos anos 90. Rio de Janeiro, Garamond, 2005.

Foucault, Michel. Microfísica do Poder. São Paulo, Ed. Graal, 2003.

FRY, Peter e MACRAE, Edward. O que é homossexualidade. São Paulo, Brasiliense, 1983.

GUIMARÃES, Kátia e MERCHÁN-HAMANN, Edgar. Comercializando fantasias: a representação social da prostituição, dilemas da profissão e a construção da cidadania. Revista Estudos Feministas, vol.13, n 3 , Florianópolis, UFSC, 2005, pp.507-525.

Grossi, Miriam, Minella, Luzinete e MENDES, Juliana. Gênero e Violência. Pesquisas acadêmicas brasileiras (1975-2005). Ilha de Santa Catarina, Ed. Mulheres, 2006.

HARDING, Sandra. Whose science? Whose knowledge? Ithaca, NY, Cornell University Press, 1991.

HARDING, Sandra. Rethinking feminist standpoint epistemology: What is "strong objectivity"? In: AlCOFF, L. \& POTTTF, E. (eds.). Feminist epistemologies. NewYork, Routledge, 1993, pp.49-82.

HARDING, Sandra. Introduction: Standpoint theory as a site of political, philosophic, and scientific debate. In: HARDING, Sandra (ed.). The feminist standpoint theory reader: Intellectual $a d$ political controversies. New York, Routledge, 2004, pp.I-IS.

HEILBORN, Maria Luiza. Ser ou estar homossexual: dilemas de construção de identidade social. In: PARKER, Richard e BARBOSA, Regina Maria (orgs.). Sexualidades brasileiras. Rio de Janeiro, Relume Dumará, 1996, pp.136-145.

MACCORMACK, Carol e StRATHERn, Marylin (ed.). Nature, Culture and Gender. Cambridge, Cambridge University Press, 1980. 
MACHADO, Lia Zanotta. Campo Intelectual e Feminismo, Série Antropologia n ${ }^{\circ}$ 170, Brasília, UnB, 1994.

MACHADO, Lia Zanotta. Estudos de gênero: Para além do Jogo entre Intelectuais e Feministas. In: SCHPUN, Mônica (org.). Gênero sem Fronteiras. Florianópolis, Editora das Mulheres, 1997, pp.35-78.

MACHADO, Lia Zanotta. Gênero, um novo paradigma? Cadernos Pagu (11), Campinas-SP, Núcleo de Estudos de Gênero-Pagu/Unicamp, Unicamp, 1998, pp.107-125.

MACHADO, Lia Zanotta. Onde não há igualdade. In: MORAES, Aparecida; SORJ, Bila (org.). Gênero, violência e direitos na sociedade brasileira. Rio de Janeiro, Editora 7 Letras, 2009a, vol. 1, pp.158-183.

MACHADO, Lia Zanotta. Políticas Sociais, Diversidade Cultural e Igualdade de Gênero. In: SILVA, C.; LIMA, A.C.; BAINES, S (org.). Problemáticas Sociais para Sociedades Plurais - Politicas indigenistas, sociais e de desenvolvimento em perspectiva comparada. São Paulo, Annablume, vol. 1, 2009b, pp.109-128,.

MACHADO, Lia Zanotta. Feminismo em Movimento. São Paulo, Editora Francis, 2010.

MAHMOOD, Saba. Politics of Piety: the islamic revival and the feminist subject. Princeton e Oxford, Princeton University Press, 2005.

MACRAE, Edward. A construção da igualdade. Identidade sexual e política no Brasil da "abertura". Campinas, Ed. da Unicamp, 1990.

MoORE, Henrietta. The Subject of Anthropology: gender, symbolism and psychoanalysis. Cambridge e Malden, Polity Press, 2007.

Pimentel, Silvia, PANDJiARJiAn, Valéria e Belloque, Juliana. Legítima Defesa da Honra. Ilegítima impunidade de assassinos. São Paulo, CLADEM, 2004.

PISCITELl, Adriana. Trânsitos: Brasileiras nos mercados transnacionais do sexo. Rio de Janeiro, CLAM/EdUerj, 2013.

RiBeIRO, Gustavo. World Anthropologies Cosmopolitics for a new global scenario in Anthropology. Série Antropologia n 377,Brasília, 2005.

RIBEIRO, Gustavo. Cultural Diversity as a Global Discourse. Série Antropologia $\mathrm{n}^{\circ}$ 412, Brasília, 2007. 
SEGATO, Rita Laura. Antropología y derechos humanos: alteridad y ética en el movimiento de los derechos universales. Série Antropologia, $\mathrm{n}^{\circ}$ 356, Brasília, 2004.

Simĩã, Daniel Schroeter. As Donas da Palavra. Gênero, Justiça e a Invenção da Violência Doméstica em Timor Leste. Tese de Doutorado em Antropologia, Brasília, UnB, 2005.

SPIVAK, Gayatri. Afterword. In: MAHASWETA, Devi. Imaginary Maps. New York and London, Routledge, 1995, pp.197-205.

STRATHERN, Marilyn. The Gender of the Gift. Berkeley, University of California Press, 1988.

VALE DE ALmeIDA, Miguel. Antropologia e Sexualidade. Consensos e Conflitos Teóricos em Perspectiva Histórica. In: FONSECA, SOARES e VAZ (org.). A Sexologia, Perspectiva Multidisciplinar. Coimbra, Quarteto, vol. II, 2003, pp.53-72. Disponível em: $<$ https://www.yumpu.com/pt/document/view/12040570/antropologiae-sexualidade-miguel-vale-de-almeidapdf $>$.

ViannA, A. e LACERDA, P. Direitos e Políticas Sexuais no Brasil. O panorama atual. Rio, CEPESC, 2004.

WiLSON, Richard. Human Rights, Culture and Context. Anthropological perspectives. London, Chicago Press, 1997. 